\title{
Morphological parameters as factors of 12-month neurological worsening in surgical treatment of patients with unruptured saccular intracranial aneurysms: importance of size ratio
}

\author{
Hidetoshi Matsukawa, MD, PhD, ${ }^{1}$ Hiroyasu Kamiyama, MD, ${ }^{1}$ Yu Kinoshita, MD, ${ }^{1}$ \\ Norihiro Saito, MD, PhD, ${ }^{1}$ Yuto Hatano, MD, ${ }^{1}$ Takanori Miyazaki, MD, ${ }^{1}$ Nakao Ota, MD, ${ }^{1}$ \\ Kosumo Noda, MD, ${ }^{1}$ Takaharu Shonai, MD, ${ }^{2}$ Osamu Takahashi, MD, MPH, PhD, ${ }^{3}$ \\ Sadahisa Tokuda, MD, ${ }^{1}$ and Rokuya Tanikawa, MD1
}

\begin{abstract}
${ }^{1}$ Department of Neurosurgery, Stroke Center, and ${ }^{2}$ Department of Radiology, Teishinkai Hospital, Sapporo; and ${ }^{3}$ Center for Clinical Epidemiology, Internal Medicine, St. Luke's International Hospital, Tokyo, Japan
\end{abstract}

\begin{abstract}
OBJECTIVE It is well known that larger aneurysm size is a risk factor for poor outcome after surgical treatment of unruptured saccular intracranial aneurysms (USIAs). However, the authors have occasionally observed poor outcome in the surgical treatment of small USIAs and hypothesized that size ratio has a negative impact on outcome. The aim of this paper was to investigate the influence of size ratio on outcome in the surgical treatment of USIAs.

METHODS Prospectively collected clinical and radiological data of 683 consecutive patients harboring 683 surgically treated USIAs were evaluated. Dome-to-neck ratio was defined as the ratio of the maximum width of the aneurysm to the average neck diameter. The aspect ratio was defined as the ratio of the maximum perpendicular height of the aneurysm to the average neck diameter of the aneurysm. The size ratio was calculated by dividing the maximum aneurysm diameter (height or width, $\mathrm{mm}$ ) by the average parent artery diameter $(\mathrm{mm})$. Neurological worsening was defined as an increase in modified Rankin Scale score of 1 or more points at 12 months. Clinical and radiological variables were compared between patients with and without neurological worsening.
\end{abstract}

RESULTS The median patient age was 64 years (IQR 56-71 years), and 528 (77\%) patients were female. The median maximum size, dome-to-neck ratio, aspect ratio, and size ratio were $4.7 \mathrm{~mm}$ (IQR 3.6-6.7 mm), 1.2 (IQR 1.0-1.4), 1.0 (IQR 0.76-1.3), and 1.9 (IQR 1.4-2.8), respectively. The size ratio was significantly correlated with maximum size $(r=$ $0.83, p<0.0001)$, dome-to-neck ratio $(r=0.69, p<0.0001)$, and aspect ratio $(r=0.74, p<0.0001)$. Multivariate logistic regression analysis showed that the specific USIA location (paraclinoid segment of the internal carotid artery: OR 6.2, $95 \% \mathrm{Cl} 2.6-15, \mathrm{p}<0.0001$; and basilar artery: OR 8.4, 95\% Cl 2.8-25, $\mathrm{p}<0.0001)$, size ratio (OR 1.3, 95\% $\mathrm{Cl} 1.1-1.6$, $p=0.021$ ), and postoperative ischemic lesion (OR 9.4, 95\% Cl 4.4-19, $p<0.0001$ ) were associated with neurological worsening $(n=52,7.6 \%)$, and other characteristics showed no significant differences.

CONCLUSIONS The present study showed that size ratio, and not other morphological parameters, was a risk factor for 12-month neurological worsening in surgically treated patients with USIAs. The size ratio should be further studied in a large, prospective observational cohort to predict neurological worsening in the surgical treatment of USIAs.

https://thejns.org/doi/abs/10.3171/2018.4.JNS173221

KEYWORDS intracranial aneurysm; morphology; patient outcome assessment; surgical procedures; vascular disorders

$\mathrm{I}$ NTRACRANIAL aneurysms have a prevalence of almost $5 \%$ in the general population..$^{1,3}$

It is well known that a larger aneurysm size is a risk factor for rupture of unruptured intracranial aneurysms, $, 4,7,10,13,16,17,28$ with poor outcomes after surgical treatment. ${ }^{5,6,8,18-20,29}$ However, the ratio between aneurysm diameter and parent artery diameter (size ratio), and not the absolute size, has been recently shown to be related to the rupture of unruptured saccular intracranial aneurysms (USIAs). ${ }^{11,21}$ An increased size ratio resulted in more complex flow patterns, multiple vortices, and low aneurysm wall shear stress. ${ }^{23}$ To date, whether size ratio is related 
to poor outcome in the surgical treatment of USIAs remains uncertain. Because we have occasionally observed poor outcome after the surgical treatment of relatively small USIAs, we hypothesized that size ratio might have a negative impact on outcome and aimed to investigate the influence of size ratio on neurological worsening in the surgical treatment of USIAs.

\section{Methods}

The study is reported based on criteria from the STROBE (Strengthening the Reporting of Observational Study in Epidemiology) statement. ${ }^{27}$ The study protocol was approved by the institutional ethics committee. $\mathrm{Pa}$ tient consent was obtained in each case. We recommend treatment of symptomatic and asymptomatic intracranial aneurysms larger than $7 \mathrm{~mm}$; however, we do not refuse to treat smaller aneurysms $(3-7 \mathrm{~mm})$ if patients express a strong desire to have them treated after being informed of the natural history of intracranial aneurysms and the associated morbidity and mortality of surgical clipping. Surgical indications for the treatment of intracranial aneurysms have been recently described. ${ }^{15}$ Patients who wish to undergo endovascular treatment are referred to other hospitals. Those who hope to have their aneurysms treated medically undergo follow-up in our outpatient depart- ment. Regardless of age, we do not perform direct surgery in patients who have cardiovascular disease or are intolerant to general anesthesia, and in those with uncontrollable diabetes mellitus. Inclusion criteria are shown in Fig. 1. Between April 2012 and December 2016, 3100 patients were diagnosed with intracranial aneurysms at the Department of Neurosurgery at Teishinkai Hospital. Among these patients, 1991 patients were treated conservatively in the outpatient department. After exclusion of 426 patients, 683 patients with 683 USIAs participated in the present study (202 patients with a total of 403 USIAs were excluded because it could not be determined which USIA was causing the neurological worsening).

Clinical data were obtained through a review of the patient medical records and checklists and included demographic information, such as age and sex. We also collected the following data: body mass index $\left(\mathrm{kg} / \mathrm{m}^{2}\right)$, smoking history (current vs former/never), alcohol consumption status (consuming or not consuming alcohol more than 5 days a week), medical history (hypertension, dyslipidemia, and diabetes mellitus), medications (antiplatelets and anticoagulants), aneurysm location, aneurysm parameters (maximum size, height, neck width, and parent artery), whether an aneurysm was thrombosed, and postoperative ischemic lesions on postoperative diffusion-weighted MR imaging. An experienced radiologist (T.S.) who was blind-

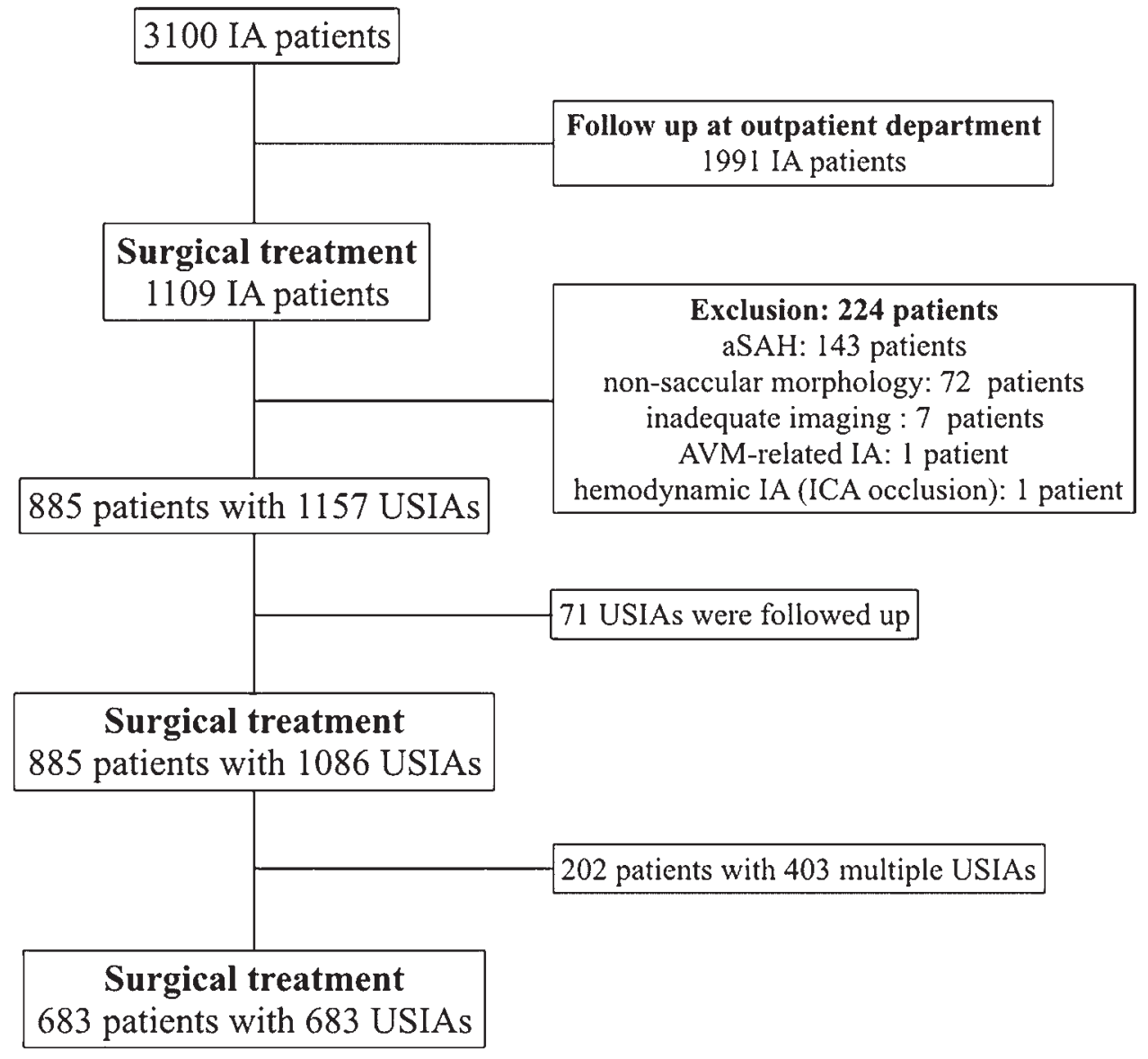

FIG. 1. Exclusion criteria. aSAH = aneurysmal subarachnoid hemorrhage; $A V M=$ arteriovenous malformation; $I A=$ intracranial aneurysm; ICA = internal carotid artery. 
ed to the clinical data evaluated the radiological characteristics. Information regarding smoking history and past medical history was obtained from the patients, their family members, and/or their physicians.

Parent artery diameter was measured at the nearest region of the definable artery for all arteries that had direct contact with the aneurysm neck (in the case of a sidewall aneurysm, the region of the artery on the proximal side of the aneurysm was used). ${ }^{21}$ With aneurysms whose orifice directly involved more than a single parent artery, for the purposes of size ratio calculation, a mean parent artery diameter was used (generated by averaging each of the involved arteries). The size ratio was calculated by dividing the maximum aneurysm size (height or width, $\mathrm{mm}$ ) by the average parent artery diameter $(\mathrm{mm})$. Dome-to-neck ratio was the ratio of the maximum width of the aneurysm to the average neck diameter. Aspect ratio was the ratio of the maximum perpendicular height of the aneurysm to the average neck diameter of the aneurysm. ${ }^{24}$

Outcome was assessed using the modified Rankin Scale (mRS) score at the 30-day, 6-month, and 12-month follow-up examinations or the last hospital visit, ${ }^{25}$ either by telephone interviews with the patient or family members or during a physical examination performed by a blinded assessor for patients who were able to visit our hospital (T.M., independently of the primary surgeon). Neurological worsening was defined as an increase in the mRS score by 1 or more points.

\section{Statistical Analysis}

Statistical analysis was performed using IBM SPSS for Macintosh (version 21.0, IBM Corp.). Variables are expressed as the mean, median (with interquartile range [IQR], 25th-75th percentile), or number of patients (\%), as appropriate. Fisher exact tests were performed for nominal variables. Pearson chi-square tests were used to assess associations between categorical variables, complemented by adjusted residual analysis. The normality of the data was evaluated using the Shapiro-Wilk test. Normally distributed continuous variables were compared using the Student t-test and nonnormally distributed variables using the Mann-Whitney U-test. The correlation among aneurysm morphological parameters was evaluated by simple regression analysis. Variables were compared between patients with and without 30-day, 6-month, and 12-month neurological worsening by univariate analysis. A multivariate logistic regression analysis was performed using variables that were significantly or marginally $(p<0.20)$ associated with the neurological worsening by univariate analysis. Differences were considered significant at $\mathrm{p}<$ 0.05 .

\section{Results}

The median age of the 683 patients was 64 years (IQR 56-71 years) and $528(77 \%)$ patients were female. Type of surgical treatment was as follows: neck clipping ( $\mathrm{n}=$ $618,90 \%)$, proximal clipping $(\mathrm{n}=32,4.7 \%)$, trapping ( $\mathrm{n}$ $=23,3.4 \%)$, and partial clipping $(\mathrm{n}=10,1.5 \%)$. Bypass surgery was performed in 91 patients (13\%). The median aneurysm morphological parameters were as follows: maximum size, $4.7 \mathrm{~mm}$ (IQR 3.6-6.7 $\mathrm{mm}$ ); dome-to-neck ratio, 1.2 (IQR 1.0-1.4); aspect ratio, 1.0 (IQR 0.76-1.3); and size ratio, 1.9 (IQR 1.4-2.8). The mean maximum size was $6.6 \mathrm{~mm}$, and the mode was $3.7 \mathrm{~mm}$. The size ratio was significantly correlated with maximum size $(\mathrm{r}=0.83$, $\mathrm{p}<0.0001)$, dome-to-neck ratio $(\mathrm{r}=0.69, \mathrm{p}<0.0001)$, and aspect ratio $(r=0.74, p<0.0001)$. Postoperative MR imaging was performed in all patients and revealed ischemic lesions in 61 patients (8.9\%). Among these patients, perforator territory infarctions were observed in 35 patients, nonperforator artery territory infarction in 23 patients, and venous infarction in 3 patients. The outcomes according to mRS scores are shown in Table 1. A good outcome (mRS score 2) was achieved in 59 (8.6\%), 36 (5.3\%), and $19(2.8 \%)$ patients at 30 days, 6 months, and 12 months, respectively. An excellent (mRS score $0-1$ ) outcome was achieved in 601 (88\%), 630 (93\%), and 648 (95\%) patients at 30 days, 6 months, and 12 months, respectively. Neurological worsening at 30 days, 6 months, and 12 months was observed in $152(22 \%), 65(9.5 \%)$, and 52 patients (7.6\%), respectively. During the follow-up period (median 765 days, IQR 435-1143 days), one patient died of postUSIA treatment rupture 29 days after aneurysm surgery, and another patient died of anticoagulant-related intracerebral hemorrhage (international normalized ratio $>10$ ) 10 months after the surgery. Therefore, the cumulative mortality rate was $0.29 \%$.

The results of univariate analysis for neurological worsening are shown in Table 2. The proportion of patients with daily alcohol consumption was marginally smaller in patients with 30 -day neurological worsening $(\mathrm{p}<0.20)$. Proportions of previously treated recurrent USIAs, thrombosed USIAs, the specific aneurysm location (paraclinoid segment of the internal carotid artery and the distal basilar artery), and postoperative ischemic lesions were significantly larger in patients with 30-day neurological worsening $(p<0.05)$. Aspect ratio and size ratio of the aneurysms in patients with 30-day neurological worsening were marginally larger than those in patients without 30 -day neurological worsening. The maximum aneurysm size in patients with 30-day neurological worsening was significantly larger than that in those without 30-day neurological worsening.

The proportions of previously treated recurrent USIAs, thrombosed USIAs, distal basilar artery aneurysms, and postoperative ischemic lesions were significantly larger in patients with 6-month neurological worsening. The

TABLE 1. Outcomes according to the $\mathrm{mRS}$ score

\begin{tabular}{ccccc}
\hline & \multicolumn{4}{c}{ No. of Patients (\%) } \\
\cline { 2 - 5 } $\begin{array}{c}\text { mRS } \\
\text { Score }\end{array}$ & $\begin{array}{c}\text { Preop } \\
(\mathrm{n}=683)\end{array}$ & $\begin{array}{c}\text { 30 Days } \\
(\mathrm{n}=683)\end{array}$ & $\begin{array}{c}6 \text { Mos } \\
(\mathrm{n}=682)\end{array}$ & $\begin{array}{c}12 \text { Mos } \\
(\mathrm{n}=682)\end{array}$ \\
\hline 0 & $617(90)$ & $486(71)$ & $577(85)$ & $601(88)$ \\
\hline 1 & $34(5.0)$ & $115(17)$ & $53(7.8)$ & $47(6.9)$ \\
\hline 2 & $25(3.7)$ & $59(8.6)$ & $36(5.3)$ & $19(2.8)$ \\
\hline 3 & $4(0.6)$ & $11(1.6)$ & $7(1.0)$ & $6(0.9)$ \\
\hline 4 & $3(0.4)$ & $3(0.4)$ & $3(0.4)$ & $3(0.4)$ \\
\hline 5 & & $7(1.0)$ & $5(0.7)$ & $5(0.7)$ \\
\hline 6 & $1(0.15)$ & $1(0.15)$ \\
\hline
\end{tabular}


TABLE 2. Characteristics between patients with and without 12-month neurological worsening

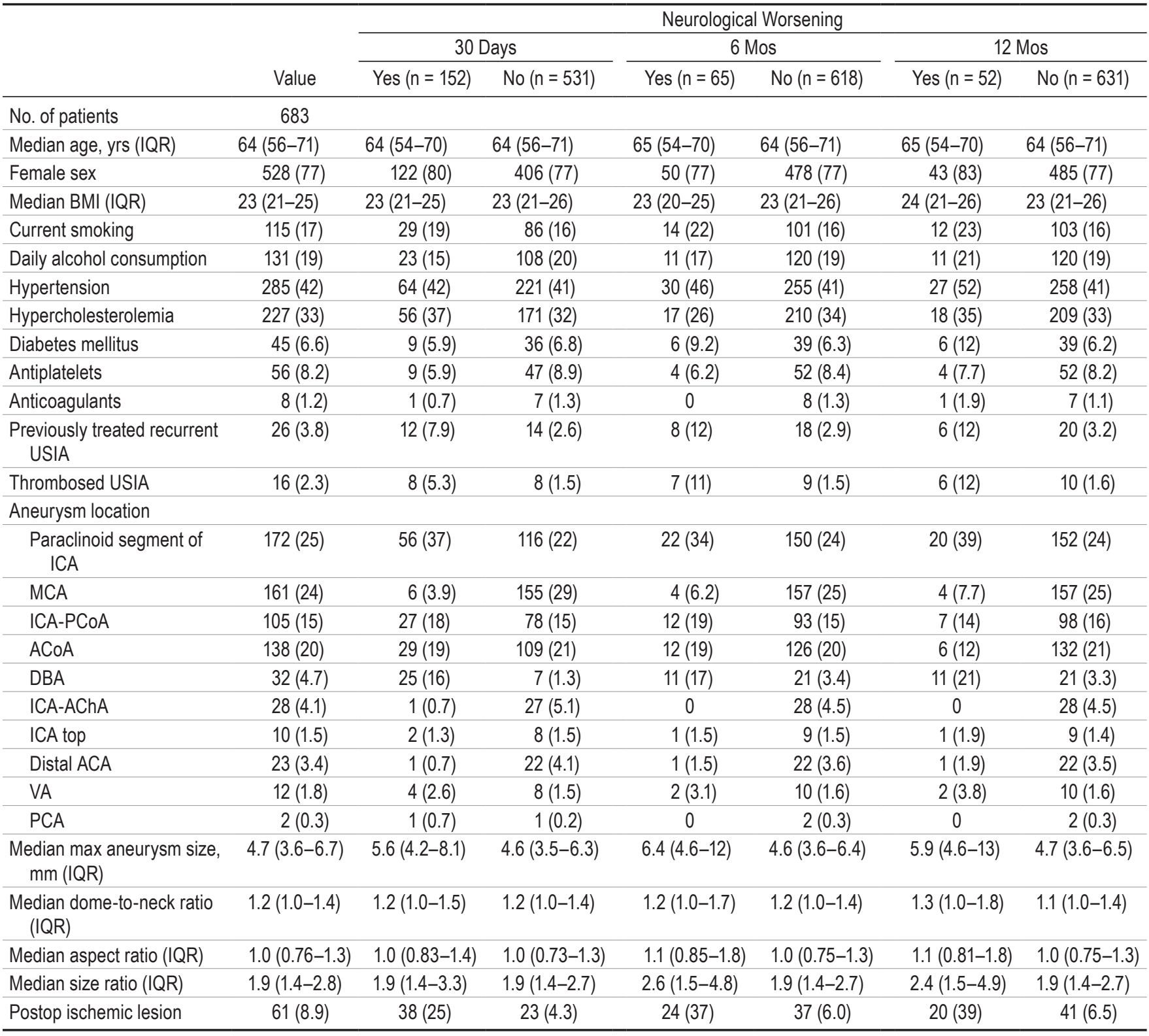

$\mathrm{ACA}=$ anterior cerebral artery; $\mathrm{AChA}=$ anterior choroidal artery; $\mathrm{ACOA}=$ anterior communicating artery; $\mathrm{DBA}=$ distal basilar artery; ICA = internal carotid artery; max = maximum; $\mathrm{MCA}=$ middle cerebral artery; $\mathrm{PCA}=$ posterior cerebral artery; $\mathrm{PCo}=$ = posterior communicating artery; $\mathrm{VA}=$ vertebral artery.

Data are expressed as the number of patients (\%) unless otherwise indicated.

dome-to-neck ratio in patients with 6-month neurological worsening was marginally larger than that in patients without 6-month neurological worsening. The maximum aneurysm size, aspect ratio, and size ratio in patients with 6-month neurological worsening were significantly larger than those in patients without 6-month neurological worsening.

Proportions of hypertension and diabetes mellitus were marginally higher in patients with 12-month neurological worsening. Proportions of previously treated recurrent USIAs, thrombosed USIAs, the specific aneurysm location (paraclinoid segment of the internal carotid artery and the distal basilar artery), and postoperative ischemic lesions were significantly larger in patients with neurological worsening at 12 months. The dome-to-neck ratio in patients with 12-month neurological worsening was marginally larger than that in patients without 12-month neurological worsening. The maximum aneurysm size, aspect ratio, and size ratio in patients with 12 -month neurological worsening were significantly larger than those in patients without 12-month neurological worsening. There were no significant differences for the other factors between the 2 groups.

Patients with a postoperative ischemic lesion, hypertension, thrombosed USIA, and previously treated recurrent USIA had a significantly larger size ratio than those with- 


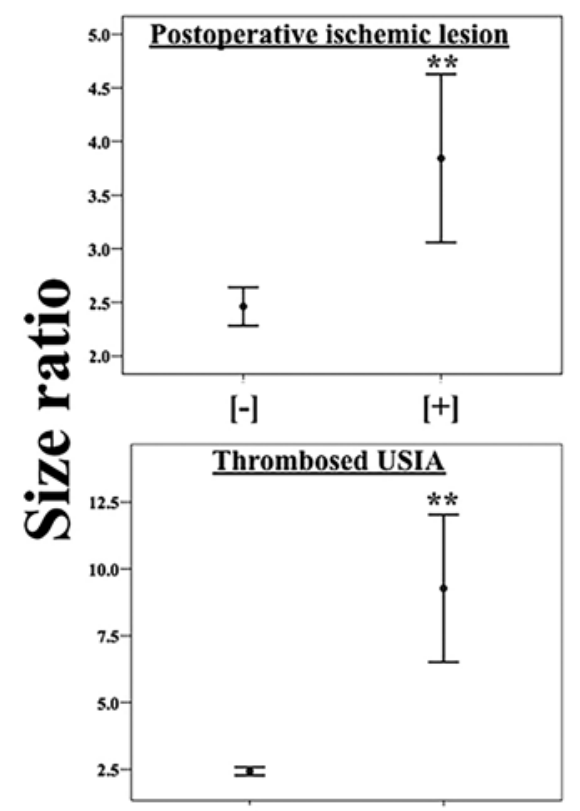

$[-]$

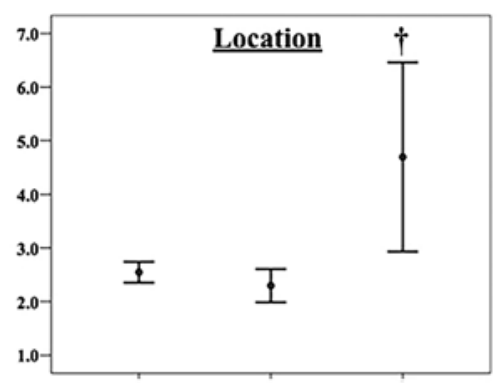

Other Paraclinoid DBA

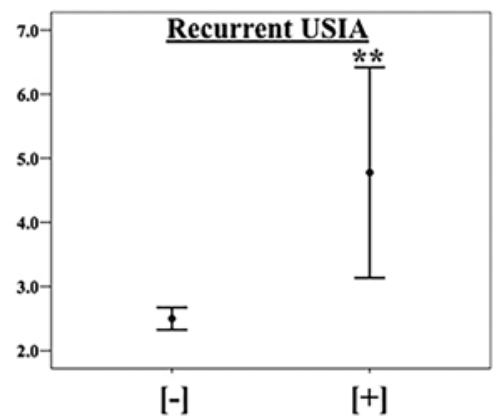

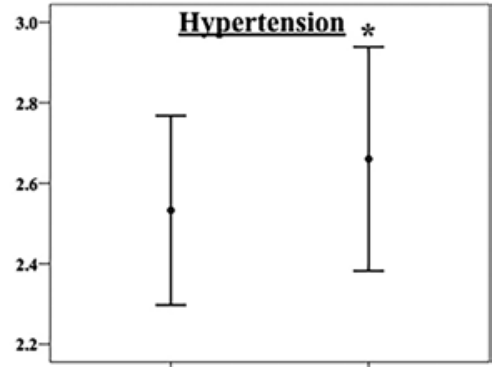

$[-]$

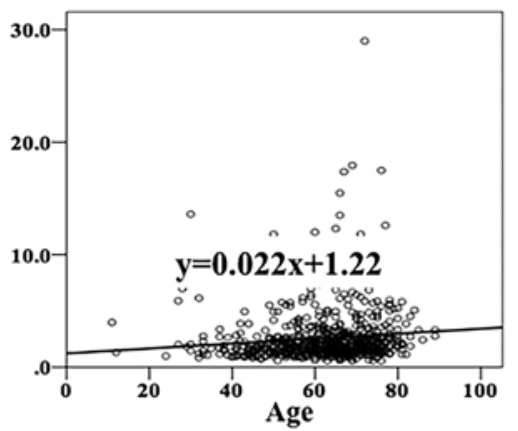

FIG. 2. Size ratio and variables with significant differences. Various symbols indicate the following levels of statistical significance and comparisons: ${ }^{*} p<0.05$ and ${ }^{* *} p<0.0001$. $\dagger$ the size ratio of the aneurysms in the distal basilar artery (DBA) is larger than that of aneurysms in the paraclinoid segment of the internal carotid artery. The size ratio is weakly correlated with age $(r=0.11, p=$ 0.005). + = present; $-=$ absent.

out these characteristics. Although age was significantly correlated with size ratio $(\mathrm{p}=0.005)$, the correlation was weak $(r=0.11)$ (Fig. 2). Therefore, age was added in the multivariate analysis. The specific aneurysm location (paraclinoid segment of the internal carotid artery and distal basilar artery), maximum aneurysm size, size ratio, and postoperative ischemic lesions were significantly related to 30-day neurological worsening on multivariate logistic regression analysis. A multivariate logistic regression analysis showed that the distal basilar artery aneurysm and postoperative ischemic lesions were significantly related to 6-month neurological worsening. It also showed that the specific aneurysm location (paraclinoid segment of the internal carotid artery and distal basilar artery), size ratio, and postoperative ischemic lesions were significantly related to neurological worsening at 12 months (Table 3).

Complications in patients with 12-month neurological worsening are shown in Table 4. Other complications included incidental embolic cerebral infarction $(\mathrm{n}=2)$, hypertensive intracerebral hemorrhage $(\mathrm{n}=1)$, and worsening of dementia $(n=1)$. The size ratio of patients with postoperative ischemic lesion and cerebral contusion was significantly larger than that of patients without neurological worsening. The size ratio of aneurysms in patients with cranial nerve symptoms and other complications showed no significant difference.

\section{Discussion}

The results of the present study show that size ratio, rather than other aneurysm morphological characteristics, is a risk factor for 12-month neurological worsening in patients with surgically treated USIAs.
Because of the high morbidity and mortality of ruptured intracranial aneurysms, there is consensus that the prevention of hemorrhage is a desirable strategy. Data in the present study indicate that, as a result of the advancements in microsurgery and neurophysiological monitoring methods, surgical treatment for USIAs can be performed more safely and with more justification. However, other studies have shown controversy as to the optimal treatment strategy because of considerable complication rates and treatment mortality. ${ }^{16,26}$ In this regard, good and excellent outcomes (mRS scores 0-2) and excellent outcome alone (mRS score 0 or 1) at 12 months were achieved in 98\% and 95\% patients, respectively. However, given that 12 -month neurological worsening was observed in 52 patients $(7.6 \%)$ with a mortality rate of $0.29 \%$, surgical outcome needs improvement.

Previous studies demonstrated that larger aneurysm size was one of the most important risk factors associated with a poor outcome after aneurysm treatment. ${ }^{5,6,8,18-20 \text {, }}$ ${ }^{22,29}$ In addition, Kassell et al..$^{12}$ indicated that a large aneurysm size was also one of the prognostic factors related to mortality. However, none of these studies evaluated the importance of the size ratio on surgical outcome. In addition, although we revealed that the size ratio, and not the absolute size, was related to 12-month neurological worsening in patients with surgically treated unruptured nondissecting anterior cerebral artery aneurysms, ${ }^{14}$ whether size ratio was related to surgical outcome of USIAs remains uncertain. The size ratio of the aneurysms in patients with postoperative ischemic lesions was larger than that in patients without postoperative ischemic lesions. In addition, regardless of the correlation among size ratio, 
TABLE 3. Multivariate logistic regression analysis for the neurological worsening

\begin{tabular}{|c|c|c|c|}
\hline Variable & OR & $95 \% \mathrm{Cl}$ & $p$ Value \\
\hline \multicolumn{4}{|l|}{ 30-day } \\
\hline Age & 0.99 & $0.98-1.0$ & 0.85 \\
\hline Daily alcohol consumption & 0.81 & $0.47-1.4$ & 0.81 \\
\hline Recurrent USIA & 2.0 & $0.74-5.5$ & 0.17 \\
\hline Thrombosed USIA & 2.4 & $0.52-11$ & 0.27 \\
\hline \multicolumn{4}{|l|}{ Aneurysm location } \\
\hline Other & Reference & & \\
\hline Paraclinoid segment of ICA* & 4.6 & $2.7-7.8$ & $<0.0001$ \\
\hline Distal basilar artery* & 19 & $7.7-51$ & $<0.0001$ \\
\hline Max aneurysm size* & 0.92 & $0.85-0.98$ & 0.016 \\
\hline Aspect ratio & 0.94 & $0.65-1.4$ & 0.76 \\
\hline Size ratio & 1.2 & $1.1-1.4$ & 0.041 \\
\hline Postop ischemic lesion & 9.6 & $5.1-18$ & $<0.0001$ \\
\hline \multicolumn{4}{|l|}{ 6-mo } \\
\hline Age & 0.98 & $0.96-1.0$ & 0.20 \\
\hline Recurrent USIA & 2.3 & $0.76-6.8$ & 0.14 \\
\hline Thrombosed USIA & 3.4 & $0.74-15$ & 0.12 \\
\hline Distal basilar artery location* & 3.2 & $1.2-8.5$ & 0.023 \\
\hline Max aneurysm size & 1.0 & $0.96-1.1$ & 0.44 \\
\hline Dome-to-neck ratio & 0.62 & $0.35-1.1$ & 0.11 \\
\hline Aspect ratio & 1.5 & $0.79-2.7$ & 0.22 \\
\hline Size ratio & 1.0 & $0.85-1.2$ & 0.76 \\
\hline Postop ischemic lesion* & 7.9 & $4.1-15$ & $<0.0001$ \\
\hline \multicolumn{4}{|l|}{ 12-mo } \\
\hline Age & 0.99 & $0.96-1.0$ & 0.54 \\
\hline Hypertension & 1.8 & $0.93-3.7$ & 0.081 \\
\hline Diabetes mellitus & 2.5 & $0.81-7.6$ & 0.11 \\
\hline Recurrent USIA & 1.7 & $0.44-6.2$ & 0.46 \\
\hline Thrombosed USIA & 3.0 & $0.50-18$ & 0.23 \\
\hline \multicolumn{4}{|l|}{ Aneurysm location } \\
\hline Other & Reference & & \\
\hline Paraclinoid segment of ICA* & 6.2 & $2.6-15$ & $<0.0001$ \\
\hline Distal basilar artery* & 8.4 & $2.8-25$ & $<0.0001$ \\
\hline Max aneurysm size & 0.94 & $0.86-1.0$ & 0.22 \\
\hline Dome-to-neck ratio & 0.68 & $0.35-1.3$ & 0.26 \\
\hline Aspect ratio & 1.1 & $0.51-2.3$ & 0.83 \\
\hline Size ratio* & 1.3 & $1.1-1.6$ & 0.021 \\
\hline Postop ischemic lesion* & 9.4 & $4.4-19$ & $<0.0001$ \\
\hline
\end{tabular}

*Variables significantly related to neurological worsening.

maximum size, dome-to-neck ratio, and aspect ratio, size ratio was the only negative prognostic factor among morphological parameters in the surgical treatment of USIA after adjustment for age, hypertension, diabetes mellitus, previously treated recurrent USIA, thrombosed USIA, aneurysm location, and postoperative ischemic lesions. If the size of the USIA were the same, the USIA that arises from smaller parent arteries would have a larger size ratio. Our speculation for the relationship between a large size ratio and neurological worsening might be that USIAs with
TABLE 4. Complications and the size ratio in 52 patients with 12-month neurological worsening

\begin{tabular}{|c|c|c|}
\hline Complication & $\begin{array}{c}\text { No. of Patients } \\
(\%)\end{array}$ & $\begin{array}{c}\text { Median Size Ratio } \\
(\text { IQR) }\end{array}$ \\
\hline Postop ischemic lesion* & $20(38)$ & $3.2(1.6-4.9)$ \\
\hline Perforator infarction & $17(33)$ & $3.6(1.7-5.3)$ \\
\hline Parent artery infarction & $2(3.8)$ & $14 \& 1.5$ \\
\hline Venous infarction & $1(1.9)$ & 4.9 \\
\hline Cerebral contusion* & $5(9.6)$ & $2.6(1.4-13)$ \\
\hline Cranial nerve symptom & $23(44)$ & $1.7(1.3-3.5)$ \\
\hline Other complications & $4(7.7)$ & $1.4(0.83-2.7)$ \\
\hline
\end{tabular}

a larger size ratio may require more manipulation to the surrounding anatomical structures, such as parent artery, perforators, brain parenchyma, and vein, to secure the aneurysm neck compared with those with a smaller size ratio. The results of our statistical analysis seem to support our hypothesis.

Because recent studies indicated that a larger size ratio was related to rupture of USIAs,${ }^{11,21}$ preventive treatment for USIAs with a larger size ratio may be justified. However, the greater surgical risk should also be considered when deciding whether to perform surgical treatment of USIAs with a larger size ratio.

\section{Limitations}

Some limitations of this study should be mentioned. First, our study was retrospective with inherent limitations, leading to potential ascertainment bias. Second, indication of a surgical treatment where neurosurgeons decide, on a case-by-case basis, the preferred individual treatment causes selection bias. Third, our study was not a randomized controlled trial; therefore, the relative efficacy and safety of surgical clipping to the endovascular treatment could not be evaluated. However, because endovascular treatment and surgical clipping should be complementary methods, they should not be compared. In addition, the treatment strategy of endovascular treatment and surgical clipping is different. In fact, although the aspect ratio was related to the complex aneurysm that needed adjunctive techniques, ${ }^{2}$ it was not associated with neurological worsening in the present study. Accordingly, a direct comparison of the influence of the size ratio on outcome between endovascular treatment and surgical clipping is thought to be difficult. Fourth, whether confounding medical comorbidities, which were not evaluated in this study, might be a cause of the neurological worsening could not be ruled out. Given our study limitations, these findings should be considered hypothesis-generating at present, and future studies are needed to replicate these results in prospective cohorts.

\section{Conclusions}

The results of the present study showed that size ratio, and not other aneurysmal morphological parameters, was 
a risk factor for 12-month neurological worsening in the surgical treatment of USIAs. Although all USIAs should be carefully considered for surgical treatment, those with larger size ratios should perhaps be discussed in even greater depth. Careful consideration of surgical risk and detailed informed consent are necessary for USIA patients with large size ratios.

\section{References}

1. Backes D, Vergouwen MD, Tiel Groenestege AT, Bor AS, Velthuis BK, Greving JP, et al: PHASES score for prediction of intracranial aneurysm growth. Stroke 46:1221-1226, 2015

2. Brinjikji W, Cloft HJ, Kallmes DF: Difficult aneurysms for endovascular treatment: overwide or undertall? AJNR Am J Neuroradiol 30:1513-1517, 2009

3. Caranci F, Briganti F, Cirillo L, Leonardi M, Muto M: Epidemiology and genetics of intracranial aneurysms. Eur J Radiol 82:1598-1605, 2013

4. Chalouhi N, Hoh BL, Hasan D: Review of cerebral aneurysm formation, growth, and rupture. Stroke 44:3613-3622, 2013

5. Choi IS, David C: Giant intracranial aneurysms: development, clinical presentation and treatment. Eur J Radiol 46:178-194, 2003

6. Dengler J, Maldaner N, Gläsker S, Endres M, Wagner M, Malzahn U, et al: Outcome of surgical or endovascular treatment of giant intracranial aneurysms, with emphasis on age, aneurysm location, and unruptured aneuryms - a systematic review and meta-analysis. Cerebrovasc Dis 41:187-198, 2016

7. Greving JP, Wermer MJ, Brown RD Jr, Morita A, Juvela S, Yonekura M, et al: Development of the PHASES score for prediction of risk of rupture of intracranial aneurysms: a pooled analysis of six prospective cohort studies. Lancet Neurol 13:59-66, 2014

8. Hauck EF, Wohlfeld B, Welch BG, White JA, Samson D: Clipping of very large or giant unruptured intracranial aneurysms in the anterior circulation: an outcome study. J Neurosurg 109:1012-1018, 2008

9. Ishibashi T, Murayama Y, Urashima M, Saguchi T, Ebara M, Arakawa H, et al: Unruptured intracranial aneurysms: incidence of rupture and risk factors. Stroke 40:313-316, 2009

10. Juvela S, Poussa K, Lehto H, Porras M: Natural history of unruptured intracranial aneurysms: a long-term follow-up study. Stroke 44:2414-2421, 2013

11. Kashiwazaki D, Kuroda S: Size ratio can highly predict rupture risk in intracranial small $(<5 \mathrm{~mm})$ aneurysms. Stroke 44:2169-2173, 2013

12. Kassell NF, Torner JC, Haley EC Jr, Jane JA, Adams HP, Kongable GL: The International Cooperative Study on the Timing of Aneurysm Surgery. Part 1: Overall management results. J Neurosurg 73:18-36, 1990

13. Korja M, Lehto H, Juvela S: Lifelong rupture risk of intracranial aneurysms depends on risk factors: a prospective Finnish cohort study. Stroke 45:1958-1963, 2014

14. Matsukawa H, Kamiyama H, Miyazaki T, Kinoshita Y, Noda $\mathrm{K}$, Ota N, et al: Impacts of a size ratio on outcome in patients with surgically treated unruptured nondissecting anterior cerebral artery aneurysms. World Neurosurg 111:e250-e260, 2018

15. Matsukawa H, Kamiyama H, Tsuboi T, Noda K, Ota N, Miyata $\mathrm{S}$, et al: Is age a risk factor for poor outcome of surgical treatment of unruptured intracranial aneurysms? World Neurosurg 94:222-228, 2016

16. Morita A, Kirino T, Hashi K, Aoki N, Fukuhara S, Hashimoto N, et al: The natural course of unruptured cerebral aneurysms in a Japanese cohort. N Engl J Med 366:2474-2482, 2012
17. Murayama Y, Takao H, Ishibashi T, Saguchi T, Ebara M, Yuki I, et al: Risk analysis of unruptured intracranial aneurysms: prospective 10-year cohort study. Stroke 47:365-371, 2016

18. Nakase H, Shin Y, Kanemoto Y, Ohnishi H, Morimoto T, Sakaki T: Long-term outcome of unruptured giant cerebral aneurysms. Neurol Med Chir (Tokyo) 46:379-386, 2006

19. Ponce FA, Albuquerque FC, McDougall CG, Han PP, Zabramski JM, Spetzler RF: Combined endovascular and microsurgical management of giant and complex unruptured aneurysms. Neurosurg Focus 17(5):E11, 2004

20. Raaymakers TW, Rinkel GJ, Limburg M, Algra A: Mortality and morbidity of surgery for unruptured intracranial aneurysms: a meta-analysis. Stroke 29:1531-1538, 1998

21. Rahman M, Smietana J, Hauck E, Hoh B, Hopkins N, Siddiqui A, et al: Size ratio correlates with intracranial aneurysm rupture status: a prospective study. Stroke 41:916-920, 2010

22. Solomon RA, Fink ME, Pile-Spellman J: Surgical management of unruptured intracranial aneurysms. J Neurosurg 80:440-446, 1994

23. Tremmel M, Dhar S, Levy EI, Mocco J, Meng H: Influence of intracranial aneurysm-to-parent vessel size ratio on hemodynamics and implication for rupture: results from a virtual experimental study. Neurosurgery 64:622-631, 2009

24. Ujiie H, Tamano Y, Sasaki K, Hori T: Is the aspect ratio a reliable index for predicting the rupture of a saccular aneurysm? Neurosurgery 48:495-503, 2001

25. van Swieten JC, Koudstaal PJ, Visser MC, Schouten HJ, van Gijn J: Interobserver agreement for the assessment of handicap in stroke patients. Stroke 19:604-607, 1988

26. Vlak MH, Rinkel GJ, Greebe P, Algra A: Risk of rupture of an intracranial aneurysm based on patient characteristics: a case-control study. Stroke 44:1256-1259, 2013

27. von Elm E, Altman DG, Egger M, Pocock SJ, Gøtzsche PC, Vandenbroucke JP: The Strengthening the Reporting of Observational Studies in Epidemiology (STROBE) statement: guidelines for reporting observational studies. Lancet 370:1453-1457, 2007

28. Wermer MJ, van der Schaaf IC, Algra A, Rinkel GJ: Risk of rupture of unruptured intracranial aneurysms in relation to patient and aneurysm characteristics: an updated metaanalysis. Stroke 38:1404-1410, 2007

29. Wiebers DO, Whisnant JP, Huston J III, Meissner I, Brown RD Jr, Piepgras DG, et al: Unruptured intracranial aneurysms: natural history, clinical outcome, and risks of surgical and endovascular treatment. Lancet 362:103-110, 2003

\section{Disclosures}

Dr. Tanikawa: patent holder with Medical U\&A and Takayama Instrument.

\section{Author Contributions}

Conception and design: Tanikawa, Matsukawa, Kamiyama. Acquisition of data: Tanikawa, Matsukawa, Kamiyama, Kinoshita, Saito, Hatano, Miyazaki, Ota, Noda. Analysis and interpretation of data: Matsukawa. Drafting the article: Matsukawa. Reviewed submitted version of manuscript: Tanikawa, Matsukawa. Statistical analysis: Matsukawa, Takahashi. Administrative/technical/material support: Tanikawa, Kamiyama, Kinoshita, Saito, Miyazaki, Ota, Noda, Tokuda. Study supervision: Tanikawa, Kamiyama. Radiological analysis: Shonai.

\section{Correspondence}

Rokuya Tanikawa: Teishinkai Hospital, Hokkaido, Japan. taniroku@gmail.com. 